УДК 378.016: 33(470+571)(09)

ББК 74.483:65(2Рос)

DOI 10.17150/2308-2588.2017.18(3).423-442

А. А. Бессолицын

Институт российской истории РАН, Московская высшая школа сочиальных и экономических наук, г. Москва, Российская Федерация

\title{
KOMMЕРИЕСКОЕ ОБРАЗОВАНИЕ В ДОРЕВОЛЮЦИОННОЙ РОССИИ: ПЕРСПЕКТИВЫ И ОГРАНИЧЕНИЯ
}

Аннотация. В статье проанализированы основные направления развития коммерческого образования как негосударственного, ориентированного на подготовку новых кадров для торговли и промышленности в условиях экономической модернизации рубежа XIX-XX вв. Рассмотрена роль государства и формировавшегося гражданского общества в создании учебных заведений нового типа и институтов, ограничивающих эту деятельность.

Ключевые слова. Коммерческое образование, С. Ю. Витте, диплом государственного образца, отраслевые съезды предпринимателей, акционерные компании, сибирские областники.

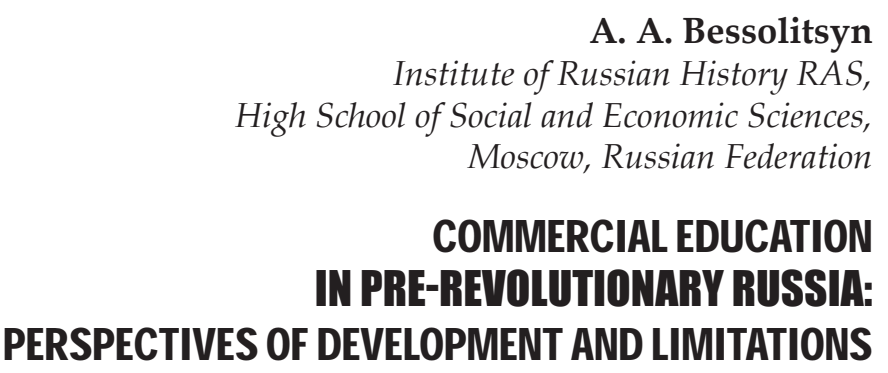

Abstract. The article analyses the basic directions of the commercial education development as non-state entity that is oriented toward the preparation of new employees for trade and industry during the economic modernization at the edge of XIX-XX centuries. The author 
studies the role of state and emerging civil society in the creation of educational institutions of the new type and institutions that limited this activity.

Keywords. Commercial education, S. Yu. Vitte, state diploma, branch entrepreneurial congresses, joint stock companies, Siberian regionalists.

История коммерческого образования как негосударственного, «...имеющего целью дать знания, полезные для торговой деятельности», берет начало еще в XVIII веке, однако, система коммерческого образования начинает активно формироваться лишь на рубеже XIX-XX вв., когда в России в условиях экономической модернизации оказались реально востребованы специалисты не только в сфере коммерции, но и в других отраслях экономики. Для страны, экономика которой была ориентирована на широкомасштабные технологические заимствования (в соответствии с догоняющей стратегией развития), необходимо было обеспечить достаточный в количественном и в качественном отношении образовательный уровень населения, чтобы заимствованные достижения были быстро освоены и дали возможность дальнейшего развития экономики уже на собственных технологических основаниях.

Решить эту проблему только за счет государственной системы образования оказалось затруднительно и государство в лице Министерства финансов выступило с инициативой преобразования существующего коммерческого образования «...в соответствии с требованиями, которые предъявляет к нему развивающаяся промышленность» [14, с. 101-102].

Эта идея была сформулирована С. Ю. Витте в программе социально-экономического развития страны, принятой в конце 1893 г. Развитие данного типа образования рассматривалось в программе в контексте решения задач модернизации, что должно было способствовать поиску новых форм управления страной с целью вывода ее экономики на уровень передовых 
государств. В решении этого вопроса Витте опирался: во-первых, на прецедент, когда 17 апреля 1881 г. Высочайшим повелением Петровское коммерческое училище С.-Петербургского купеческого общества по просьбе учредителей было выведено из подчинения Министерства народного просвещения и передано под покровительство Его Императорского Величества, а во-вторых, на постановление собрания выборных Московского купеческого сословия от 6 ноября 1889 г., в котором специально подчеркивалось, что «...отпуск Московским купеческим обществом необходимых на содержание учреждаемого при Александровском коммерческом училище технического отделения сумм будет производиться лишь при условии, если это училище и учреждаемое при нем отделение будут состоять в ведении Департамента торговли и промышленности», который, в свою очередь, находился в структуре Министерства финансов [14, с. 136-137, 141].

Таким образом, государство посредством Министерства финансов брало на себя инициативу создания институциональных (правовых, финансовых, организационных) основ функционирования системы коммерческого образования. Оборотной стороной этой политики являлся достаточно жесткий и постоянный контроль, который зависел, как правило, от политической обстановки и предполагал не только внешние формы контроля (организационный аспект), но и активное вмешательство в саму деятельность учебного заведения (изменение правил приема, решение кадровых вопросов, корректировка учебных планов, контроль за расходованием средств и т. п.).

В этой связи, сам процесс формирования коммерческого образования в России уже изначально был обусловлен рядом противоречий: с одной стороны, доминантной ролью государства в развитии модернизационных процессов и объективной необходимостью их обеспечения адекватными кадрами, а с другой, 2017. T. 18, № 3. C. 423-442 
стремлением формировавшегося гражданского общества, перехватить у правительства инициативу в целях развития прогресса и обретения обществом большей гражданской, экономической, а в конечном счете, и политической свободы.

Тем не менее, данная политика способствовала достаточно быстрому росту всей системы негосударственного образования. Всего за пять лет, с 1898 по 1903 г. были открыты 53 новых коммерческих училища, 40 торговых классов и 47 классов и курсов разных видов для взрослых [6, с. 6]. К началу 1905 г. коммерческих учебных заведений, подведомственных Министерству финансов, насчитывалось всего 191, из них 68 коммерческих училищ $(47$ - общественных и 21 частное) в 64 городах России [9, с. 1-2, 8].

Что касается высшей школы, то по данным статистики, к 1913/1914 гг. в Российской империи из 117 вузов - 54 (46 \%) были частными или общественными. Всего в высшей школе обучалось чуть более 123 тыс. человек, из них, в государственных вузах - 71 тыс., в негосударственных - 52 тыс., что составляло 42 \% от общей численности обучающихся. При этом надо отметить, что доля студентов, обучающихся в негосударственных вузах постоянно увеличивалась. Достаточно сказать, что численность студентов, обучавшихся в этих учебных заведениях с 1913 по 1917 год, выросла на 40 \% и превысила 70 тыс. человек, а численность студентов, обучавшихся в государственных вузах за тот же период, сократилась почти на 7 \% и составила примерно 63 тыс. человек [12].

На первом месте по количеству вузов и студентов в них были высшие женские педагогические и медицинские учебные заведения, на втором - собственно коммерческие вузы, которые готовили новые кадры для развивающейся промышленности и торговли. В то же время, необходимо отметить, что быстрый рост разного уровня коммерческих школ в России, по мне- 
нию дореволюционного исследователя коммерческой школы Е. Карпиньского свидетельствовал не столько о необыкновенном влечении русского юношества к коммерческому образованию как таковому, сколько в стремлении к образованию вообще. Причину сложившегося положения автор видел не только в том, что в России, в принципе, было мало образовательных учреждений разного уровня и потому, когда появилась возможность их учреждать, то общественные организации и частные лица воспользовались этим правом не задумываясь о качестве и специфике коммерческого образования, нацеленного на подготовку кадров прежде всего для развивающейся российской промышленности. Главное, по его мнению, заключалось в том, что «...хорошими учителями специальных предметов в коммерческих учебных заведениях могут быть только специалисты-практики, т.е. люди коммерческого или близкого к нему мира», а этих специалистов как раз и было недостаточно [5, с. 7-12].

Данное обстоятельство компенсировалось увеличением теоретических курсов, когда преимущество отдавалось общему образованию в ущерб специальному. Возникает феномен, который в научной литературе получил название «многопредметность». Данный термин ввел товарищ министра финансов В. И. Ковалевский, который выступая на съезде директоров и представителей попечительских советов коммерческих училищ в 1901 г. заявил, что «предметы общеобразовательные нередко подавляют специальный характер данной школы», что и приводит к многопредметности программ коммерческих училищ. В этой связи В. И. Ковалевский предлагал обдумать, «не окажется ли возможным преподавание предметов, генетически связанных между собой, вести так, чтобы они давали одно законченное целое. Равным образом, я находил бы необходимым не только согласовать программы предметов в отдельных коммерческих 2017. T. 18, № 3. C. 423-442 
училищах, но и сократить, если возможно, эти программы» [8, с. 7-8].

В отличие от российского, среднее профессиональное образование в Западной Европе в большей степени было ориентировано на практику. Надо отметить, что европейский опыт постановки специального образования активно изучался в России, особенно при организации новых технических школ, ориентированных на инновационные отрасли экономики, получившие развитие в период модернизации на рубеже XIXXX веков.

Одной из таких отраслей явилась электротехническая промышленность, которая на рубеже веков остро нуждалась в кадрах. В начале XX в. электротехнические предприятия росли опережающими темпами в основном в форме акционерно-паевых предприятий. Процесс индустриализации в России выдвинул на первый план именно акционерные компании, которым по силам были крупные, в основном иностранные инвестиции в такие капиталоемкие отрасли как машиностроение, банковское дело, строительство железных дорог, освоение новых видов природных богатств (добыча угля, нефти и др.) и т. п. Если к 1893 г. в России, судя по опубликованным балансам торгово-промышленных акционерных обществ, действовало всего 522 компании с капиталом 601 млн р., то к концу 1901 г. число таких компаний достигло 1506, а их капитал 2467 млн рублей [23, с. 165, 171].

Этот рост продолжился в годы Первой мировой войны. Только за 1914-1916 гг. открыли действия 562 отечественные и иностранные торгово-промышленные акционерные компании с капиталом 802 млн рублей [23, с. 377]. В результате, к конщу 1917 г. насчитывалось более 3000 акционерных предприятий с основным капиталом 6,7 млрд рублей [7, с. 61]. При этом надо отметить, что удельный вес производимой ими продукции во многих отраслях промышленности был домини- 
рующим, составляя 70-80, а иногда и более, процентов [2, с. 38].

Первые акционерные электротехнические предприятия в России возникли в 1880-х гг. и практически все принадлежали иностранцам. Это были в основном концессии, которые, как правило, принадлежали инвесторам из Германии. Одним из самых крупных электротехнических предприятий, принадлежащих немецкому капиталу, в России считалось «Общество электрического освещения 1886 г.». Компания была учреждена в Санкт-Петербурге в 1887 г. фирмой «Сименс и Гальске» с основным капиталом в 50 млн р. и 100 тыс. акций по 500 р. каждая. На электромеханическом и машиностроительном заводах Общества в Петербурге работало 855 человек [1, с. 334].

Общество по сути являлось «ядром всей электротехнической отрасли России». В соответствии с договором, заключенным в апреле 1887 г. с Московской городской управой ему предоставлялось право прокладывать по улицам подземные электрические провода для освещения частных помещений. Позднее, в 1895 г., вместо неопределенного и бессрочного договора владельцы получили концессию на освещение г. Москвы сроком на 50 лет, а в 1897 г. - концессию на освещение электричеством Санкт-Петербурга сроком на 40 лет [1, с 334].

Указанный объем работ требовал высокой квалификации рабочих. Дефицит российских квалифицированных кадров - как среднего звена, так и инженеров с высшим образованием - привел к тому, что значительная часть квалифицированного рабочего персонала Общества комплектовалась в основном из граждан Германии. K началу XX в. на центральной электрической станции Московского отделения работало более 140 человек [22, с. 34].

Еще более высокими темпами эта отрасль промышленности стала развиваться накануне и в годы 2017. T. 18, № 3. С. 423-442 
войны. К 1917 г. в России по данным справочника «Акционерно-паевые предприятия России» насчитывалось 54 электротехнических предприятия в основном со смешанным капиталом. Среди этих предприятий лидирующее положение занимали такие акционерные фирмы, как: “Сименс-Шукерт» (открыто в 1899 г.) с основным капиталом в 15 млн рублей. Состав предприятия: завод динамо-машин в Петербурге с отделениями в 13-ти городах; «Эриксон Л. М. и К» (открыто в 1897 г.) с основным капиталом в 4 млн рублей. Состав предприятия: телефонные и электромеханические фабрики в Петербурге и др. [1, с. 323-337]. При этом росла численность рабочих и инженеров, занятых в электротехнической отрасли. Если на телефонной фабрике «Эриксон Л. М. и К ${ }^{\circ}$ в П Петербурге в 1897 г. работало 200 человек, то в 1901 г. численность работников выросла до 500 человек [3, с. 504-505].

Электротехнические акционерные компании составляли порядка 20 \% от всех акционерных обществ, работающих в машиностроении. По темпам развития за этот короткий срок электротехническая отрасль в России предоктябрьского периода обогнала средний темп прироста капиталов в российской промышленности. Другими словами, энергетика России начала развиваться темпами, опережающими развитие экономики страны, что было непременным условием здорового состояния общества и энергетической безопасности его развития. Такие темпы требовали не только увеличения темпов роста человеческого капитала, но и повышения его качества. В этой связи необходимость подготовки национальных кадров для отрасли стояла крайне остро.

Эти вопросы являлись предметом обсуждения на Всероссийских электротехнических съездах, которые ежегодно собирались в С.-Петербурге начиная с 1899 года. Это были самые многочисленные отраслевые съезды в России. Уже на Первом съезде (1899 г.) спи- 
сок членов составил 563 человека, а на последнем Седьмом (1913 г.) список членов включал уже 760 человек, что свидетельствовало об авторитете съездов среди предпринимательского сообщества [18, с. 4-34; 19 , с. 4-24].

Практически на каждом съезде в повестку дня включался вопрос о постановке электротехнического образования. Причем, в отличие от других отраслевых организаций, электротехнические съезды рассматривали постановку всех уровней специального образования: низшего, среднего и высшего.

В докладе В. А. Ржевского «К вопросу о постановке преподавания в низших электротехнических школах» на Втором съезде в 1901 г. был сделан вывод о том, что «введение преподавания электротехники в низшие механико-технические училища не может заменить специальной электротехнической школы». При этом, «практические занятия учеников должны иметь целью обучить их механическим принципам, лежащим в основе работы, и знакомить их с основными приемами производства работ» [17, с. 173-174].

Вопрос соотношения теоретического и практического обучения в средних технических школах также являлся предметом обсуждения на съездах. В докладе И. В. Линде и Я. Ф. Каган-Шабшая «О постановке электротехнического образования», сделанном от имени Общества Московских высших электротехнических курсов в 1909 г., отмечалось, что постановка среднего электротехнического образования в Европе, в частности в Германии, предполагает выделение до $67 \%$ учебного времени на практические занятия, тогда как в аналогичных технических школах в России на практику в среднем выделяется не более 33 \% учебного времени [11, с. 16].

Этот же недостаток, даже в большей степени, был характерен и для высшей коммерческой школы, на что указал известный московский предприниматель 2017. T. 18, № 3. C. 423-442 
и общественный деятель П. А. Бурышкин, который сам, помимо юридического факультета Московского университета, окончил Московский коммерческий институт и знал ситуацию с постановкой коммерческого образования изнутри. По его мнению, коммерческая школа в России оказалась перегруженной рядом преподаваемых дисциплин и не обращала достаточного внимания на надлежащую практическую подготовку. Поэтому, как пишет автор: «Коммерческий мир и торговые организации с некоторым недоверием относились к молодым людям, кончившим институты, думая, очевидно, что в русских условиях менее требовалось знакомство с длинным рядом теоретических дисциплин по сравнению с основным знанием счетоводства или даже просто с умением считать на счетах и, несомненно, можно было отметить, что до самого последнего времени даже в таких крупных центрах, как Москва или Харьков, легче себе находили работу в торговых предприятиях молодые люди, окончившие низшие коммерческие школы» [4, с. 107].

Кроме того, выпускники высшей коммерческой школы испытывали сложности при поиске работы в государственных структурах на том основании, что они не получали дипломов государственного образца. Это положение фиксировалось в нормативных документах. Для всех уставов коммерческих учебных заведений, принятых до 1912 г., характерно отсутствие предоставления каких-либо прав лицам, их окончившим, а также прав преподавательского состава на пенсию, выслугу лет и чинопроизводство. Поэтому выпускникам этих вузов, как правило, приходилось заниматься частным предпринимательством.

Только после утверждения императором Закона о высшем коммерческом образова ᄀнии (утвержден 3 июня 1912 г.), который был опубликован в виде новых уставов Московского и Киевского коммерческих институтов, ситуация меняется. Теперь лица, полу- 
чившие дипломы об окончании высших частных или общественных учебных заведений, приобретали те же права, что и лица, обладавшие дипломами государственных вузов. Выпускники аккредитованных коммерческих вузов получали право отсрочки от военной службы и возможность по окончании учебного заведения переходить на государственную службу. Права профессуры высших общественных и частных учебных заведений были также приравнены к правам преподавателей государственных вузов.

Оборотной стороной этих изменений явилось то, что аккредитованные вузы должны были соответствовать государственным требованиям, как по перечню обязательных дисциплин, так и нормативным срокам обучения (не менее 4-х лет). Недостатком новых уставов было также то, что в них вводился ценз, связанный с вероисповеданием, чего не было предусмотрено в прежних уставах негосударственных вузов. Например, устанавливалась 5 \% норма для приема евреев, что было особенно чувствительно для Киевского коммерческого института, в котором численность этой категории студенчества достигала 40 \% [21, с. 9].

В итоге, стремление коммерческих вузов к получению дипломов государственного образца фактически привело к ограничению их автономии, свободы преподавания, введению различных ограничений при поступлении в них желающих, к усилению бюрократической опеки со стороны министерств, в ведении которых они находились.

Надо отметить, что предпринимательским сообществом делались попытки преодолеть данное обстоятельство. В частности Всероссийские электротехнические съезды выступили с инициативой учредить в Москве самостоятельное Общество Высших электротехнических курсов по типу Французской высшей электротехнической школы. Учредителями Общества стала группа лиц (всего 10 человек) имеющих непосред2017. T. 18, № 3. C. 423-442 
ственное отношение к электротехнической отрасли. Половину из них составляли практические работники, в основном инженеры-механики и электротехники ряда фирм и предприятий Москвы и Санкт-Петербурга, а вторую половину - ведущие ученые, профессора столичных отраслевых вузов.

В общих чертах характер Высших электротехнических курсов представлялся их учредителями следующим образом:

- занятия должны были происходить с утра до позднего вечера, дневные для планомерного прохождения полного курса, вечерние для отдельных лекционных циклов, рефератов;

- что касается преподавательского состава, то он должен быть в большей степени представлен практиками, связанными с электротехнической промышленностью;

- для практических и лабораторных занятий должен быть предусмотрен третий летний семестр;

- на Курсы должны были приниматься инженеры, получившие образование по другим специальностям, инженеры военные и морские, слушатели, окончившие математический факультет, а также лица, получившие повышенное среднее техническое образование;

- продолжительность обучения варьировалась в зависимости от изначальной подготовки слушателей и усвоения ими программы курсов, занимая от одного года до двух лет [20, с. 113-114].

В Положении о Высших электротехнических курсах, которое было принято Ученым советом в мае 1910 г. и утверждено Министром торговли и промышленности (11 декабря 1910 г.), Московские Высшие электротехнические курсы являлись высшим учебным заведением, имеющим целью: во-первых, предоставление электротехнических знаний лицам, получившим для этого достаточное техническое или математиче- 
ское образование, и знания в области применения электричества, во-вторых, хотя Курсы и находились в ведении Министерства торговли и промышленности, но содержаться они должны были полностью за счет Общества Московских высших электротехнических курсов.

По сути, речь шла о создании вуза, ориентированного на дополнительное образование, где нормативные сроки уже не имели какого-то определяющего значения и, в этой связи, исчезала необходимость в дипломе государственного образца, поскольку выпускники этого вуза ориентировались на работу в реальном бизнесе и не нуждались в формальном подтверждении нового уровня образования.

Однако инициатива учредить в Москве частную высшую электротехническую школу, в слушатели которой предполагалось принимать, главным образом, уже готовых инженеров, не увенчались успехом. Неудача в учреждении этого учебного заведения, как представляется, связана, прежде всего, с отсутствием необходимых средств на его открытие, собрать которые в условиях Первой мировой войны оказалось затруднительным.

Проблема финансирования коммерческих и технических школ со стороны предпринимательского сообщества особенно остро стояла в регионах.

Первыми о необходимости широкого развития среднего горнотехнического образования (путем устройства горнотехнических училищ) заявили съезды горнопромышленников Юга России, которые рассматривали его одним из главнейших условий для развития южной железоделательной промышленности. Однако главным препятствием в его практическом решении оставался финансовый вопрос. Понимая необходимость и важность подготовки профессиональных кадров, съезды не торопились брать на себя обязательства по финансированию коммерческих училищ. 2017. T. 18, № 3. C. 423-442 
Поэтому инициатива в постановке этого вопроса принадлежала, как правило, государству. В частности учреждение высшего горного училища в Екатеринославе в 1899 г. было инициировано министром земледелия и государственных имуществ, а ежегодные расходы на его содержание в размере более ста четырех тысяч рублей (с 1 января 1900 г.) были отнесены на средства государственного казначейства [10, с. 1].

Вопросы организации промышленного образования, прежде всего низшего и среднего уровня активно рассматривали съезды Уральских горнопромышленников, однако, и здесь главным препятствием в их открытии оставалась проблема финансирования. Необходимость создания на Урале целой сети низших горнотехнических школ была поднята еще на V съезде горнопромышленников в 1896 г., причем было обращено внимание на крайнюю недостаточность числа школ на Урале вообще и почти полное отсутствие низших профессиональных школ, которые готовили бы практических работников для отрасли. Съезд высказал мнение, что низшие горные школы необходимы в каждом горном округе и на каждом горном заводе [16, с. 90-91].

Результатом обсуждения вопроса «О постановке технического образования на Урале» явились поручения данные Совету съезда:

1) Возбудить перед министром торговли и промышленности ходатайство о созыве на Урале съезда деятелей по техническому образованию, при участии представителей промышленности, земств и городов Уральского края, для выработки типов и сети средних и низших технических школ на Урале.

2) Ходатайствовать о преобразовании горнозаводского отделения при Пермском Алексеевском реальном училище в самостоятельное среднее техническое училище, с открытием при нем приготовительного класса и с передачей его из Министерства народного 
просвещения в ведение Министерства торговли и промышленности.

3) Ходатайствовать о преобразовании Нижне-Тагильского и Турьинского низших технических училищ в средние технические училища.

4) Ходатайствовать об увеличении до максимума приема учеников в Уральское горное училище и о скорейшем утверждении выработанных преподавательским персоналом его новых программ этого училища [16, с. 113-115].

Анализ этих поручений позволяет сделать вывод о том, что проблема подготовки кадров низшего и среднего звена для отрасли стояла достаточно остро, однако, как следует из перечня ходатайств, с которыми должен был выступить Совет, финансовое и организационное решение этой проблемы горнопромышленники Урала хотели бы переложить на государственные и местные органы управления. Что касается определения конкретных типов специальных учебных заведений, которые следовало бы признать более целесообразными для региона и где их открытие представлялось бы более удобным, то решение этого вопроса горнопромышленники адресовали Съезду деятелей по техническому образованию, а также земствам и городам Уральского края.

По мнению Е. Ю. Рукосуева, который исследовал деятельность горно- и золотопромышленников Урала на рубеже XIX-XX вв.: «Заводовладельцы не желали авансировать капитал в дело, которое вряд ли могло принести им прибыль даже в том случае, если оно имело государственно важный характер» [15, с. 335].

В сибирском регионе, где такая форма организации предпринимательского сообщества, как отраслевые съезды, практически отсутствовала в силу недостаточного экономического развития, вопросы постановки, как общего, так и специального образования инициировали сибирские регионалисты или как их 2017. T. 18, № 3. C. 423-442 
еще именовали - областники. Феномен идеологии сибирского регионализма, зародился еще во второй половине XIX века в Петербургском кружке сибирских студентов, в который входили Григорий Потанин, Николай Ядринщев и др. В рамках областнической теории Сибирь представлялась как «обширная колония России», поскольку использовалась в основном как сырьевой придаток [13; 24]. Областники ставили вопрос о преодолении такого положения вещей и о создании условий для дальнейшего самостоятельного развития Сибири. Для решения этой задачи важная роль отводилась образованию. Именно в этом контексте рассматривался вопрос об открытии университета в Сибири. Предполагалось, что высшее образование должно решить проблему оттока молодежи из региона; обеспечить формирование сибирского чиновничества из местных жителей - знающих нужды родного края патриотов, а также создать образованный класс инженеров для поднятия сибирской промышленности.

Надо отметить, что часть этих требований в дальнейшем была реализована государством. Так, в 1888 г. в Томске был открыт первый сибирский университет, который, однако, долгие годы имел всего один факультет - медицинский, к которому в 1898 г. добавился юридический. Это было связано, как раз с неразвитостью региона и отсутствием реального спроса на конкретных специалистов. Только в начале XX века в связи с промышленным развитием региона начинают открываться технические учебные заведения, в том числе коммерческого профиля.

В частности в 1901 г. открылось первое за Уралом коммерческое училище в Томске, а в 1907 г. - Иркутское городское коммерческое училище и др. Однако первый коммерческий институт в Сибири был открыт только весной 1917 г. в Омске.

Несмотря на возникшие ограничения в постановке коммерческого (в том числе технического) образо- 
вания, его рост продолжился и в годы Первой мировой войны. Только в 1915-1916 гг. в стране было открыто в общей сложности 12 новых неправительственных вузов, в основном технического профиля. Однако после 1917 г. все частные и общественные вузы были национализированы, а вопрос о дипломе государственного образца был снят с повестки дня, поскольку в СССР все учебные заведения стали государственными.

Таким образом, несмотря на институциональные ограничения установленные государством, потенциал коммерческого образования в центральной России и, особенно, в регионах далеко не был исчерпан. Коммерческие училища и вузы начала XX века не просто ликвидировали дефицит в национальных кадрах, но и открывали новые специальности, которые практически полностью отсутствовали в государственном секторе образования (например, экономическое образование в дореволюционной России было преимущественно коммерческим).

В то же время, отраслевые съезды предпринимателей и другие общественные объединения, которые были заинтересованы в подготовке новых кадров для развивающейся промышленности, крайне неохотно брали на себя обязательства по финансированию специальных учебных заведений, перекладывая решение этой проблемы на плечи государства. Отраслевые съезды чаще всего ограничивались выделением грантов, направленных на решение частных проблем образования, в основном связанных с формированием материально-технической базы учебного заведения или назначением именных стипендий отдельным категориям обучающихся.

Поэтому создать коммерческую (техническую) школу полностью самостоятельную и финансово независимую от государства в дореволюционной России в целом и не удалось. 


\section{Список использованной литературы}

1. «Акционерно-паевые предприятия России» : сост. по офиц. дан., извлеч. из материалов, утв. общ. собр. акционеров и пайщиков, и распубл. в органах М-ва торг. и пром-сти и М-ва фин. / под общ. ред. В. В. Лаврова. - М. : М. Лавров, 1917. - 46, 613 с.

2. Барышников М. Н. Г. И. Бененсон и А. Д. Голицын: Деловое партнерство в институциональном контексте российской действительности начала XX века / М. Н. Барышников // Journal of Institutional studies (Журнал институциональных исследований). - 2015. - Т. 7, № 2. - С. 38-57.

3. Барышников М. Н. Деловой мир Петербурга: Исторический справочник / М. Н. Барышников. - СПб. : Изд-во «Logos», 2000. - 584 c.

4. Бурышкин П. А. Москва купеческая / П. А. Бурышкин. - М. : Высш. школа, 1991. - 350, [2] с.

5. Карпиньский Е. Коммерческое образование в России / Е. Карпиньский // Промышленность и торговля. - 1908. T. 2. № 13. - C. 7-12.

6. Кечеджи-Шаповалов М. В. Современноезначение коммерческого образования : речь, произнесенная на торжественном праздновании 7-й годовщины частных С.-Петербургских счетоводных курсов, учрежденных М. В. Побединским / М. В. Кечеджи-Шаповалов. - СПб.: тип. А. В. Орлова, 1905. - 15 с.

7. Лизунов П. В. Акционерные компании / П. В. Лизунов / / Экономическая история России : с древнейших времен до 1917 года : энциклопедия : в 2 т / редкол.: Ю. А. Петров (отв. ред.) [и др.]. - М. : РОССПЭН, 2008. - Т. 1 : А - М. - С. 60-62.

8. Материалы по коммерческому образованию : вып. 1 : Коммерческие училища : Съезд директоров и представителей попечит. советов в июне месяце 1901 г. в г. С.-Петербурге. СПб. : Тип. и лит. В. В. Комарова, 1901. - VIII, 163, III с

9. Материалы по коммерческому образованию: вып. 4 : Отчет о состоянии коммерческого образования в России за 1903-4 учебный год в учебных заведениях ведомства Министерства финансов. - СПб. : Тип. А. В. Орлова, 1905. - VII, 103 c.

10. Об учреждении Высшего горного училища в г. Екатеринославе и об утверждении положения о сем училище и штата оного : [утв. 4 июня 1899 г.] : Положение о Екатеринослав. высш. горн. уч-ще. -Харьков : Тип. Зильберберг, [1899]. - 16 с.

11. Общество московских высших электротехнических курсов. 1909-1911. - М., 1911. - 93 с. 
12. Осокина О. А. Становление и развитие государственно-общественной системы высшего образования в России: традиции и современность : автореф. дис. ... канд. пед. наук : специальность 13.00.01 / О. А. Осокина; [Моск. психол.-соц. ин-т]. - М., 2005. - 19 с.

13. Потанин Г. Н. Нужды Сибири / Г. Н. Потанин // Избранное / [сост. и авт. предисл. А. П. Казаркин]. - Томск : [Томская писательская организация], 2014. - С. 93-125.

14. Представление С. Ю. Витте в Государственный совет «Об изменении штатов Департамента торговли и мануфактур» // Витте С. Ю. Собрание сочинений и документальных материалов. В 5 т. Т. 4 : Промышленность, торговля и сельское хозяйство России, кн. 1 : Организация торгово-промышленного ведомства. Программы экономического развития. Акционерное учредительство / [редкол.: Н. К. Фигуровская (отв. ред.) и др.]. - М. : Наука, 2006. - 701 с.

15. Рукосуев Е. Ю. Съезды горно- и золотопромышленников Урала в конце XIX - начале XX века: организация и направления деятельности / Е. Ю. Рукосуев; науч. ред. Г. Е. Корнилов, И. В. Побережников. - Екатеринбург : УрО РАН, 2015. - 399 с.

16. Труды XIX Съезда горнопромышленников Урала с 25-го по 28-е февраля 1914 г. в г. Екатеринбурге / Совет съездов горнопромышленников Урала. - СПб., 1914. - [1], 136, $247 \mathrm{c}$.

17. Труды Второго Всероссийского электротехнического съезда 1901-1902 в Москве / под ред. А. И. Смирнова, Н. Н. Георгиевского. Т. 2. - СПб. : Постоян. ком. Всерос. электротехн. съездов, 1902. - [2], 314 с.

18. Труды Первого Всероссийского электротехнического съезда 1899-1900 в С.-Петербурге / под ред. А. И. Смирнова, Н. Н. Георгиевского. Т. 1. - СПб. : Ком. 1-го Всерос. электротехн. съезда, 1901. - Х, 308, 43 с.

19. Труды Седьмого Всероссийского электротехнического съезда 1912-1913 гг. в г. Москве. Вып. 1. - СПб. : Постоян. ком. Всерос. электротехн. съездов, 1913. - [4], 181 с.

20. Труды Шестого Всероссийского электротехнического съезда 1910-1911 гг. в С.-Петербурге. Вып. 2. - СПб. : Постоян. ком. Всерос. электротехн. съездов, 1911. - [1], 168 с.

21. Устав Киевского коммерческого института : Утв. 27 июня 1912 г. - Офиц. изд. - Киев, 1913. - [2], 23 с.

22. Фабрики и заводы г. Москвы и ее пригородов : адрес. и справ. кн. о фаб.-зав., гл. ремесл. и торгово-пром. предприя- 
тиях и др. справ. сведения / под ред. И. Ф. Горностаева. - М. : Типо-лит. «Русского т-ва печ. и изд. дела», 1904. - XVI, 275, $123 \mathrm{c}$.

23. Шепелев Л. Е. Акционерные компании в России: XIX начало XX века / Л. Е. Шепелев. - СПб. : Изд. дом С.-Петербург. гос. ун-та, 2006. - 600, [3] с.

24. Ядринцев Н. М. Сибирь, как колония в географическом, этнографическом и историческом отношении / Н. М. Ядринцев. - 2-е изд., испр. и доп. - СПб. : И. М. Сибиряков, 1892. - XII, 720 с.

\section{Информация об авторе}

Бессолицын Александр Алексеевич - доктор экономических наук, профессор, ведущий научный сотрудник, Центр экономической истории, Институт российской истории РАН, 117036, г. Москва, ул. Дмитрия Ульянова, д. 19; Московская высшая школа социальных и экономических наук, Российская Федерация, 119571, Москва, пр-т Вернадского, 82, корп. 2, e-mail: A_Bessolitsyn@mail.ru

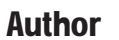

Alexander A. Bessolitsyn - D.Sc. of Economics, Professor, Leading Researcher, Centre of Economic History Institute of Russian History RAS, 19, Dmitriya Ulyanova str., Moscow; 117036; Moscow High School of Social and Economic Sciences, corp. 2, prospect Vernadskogo, 82, Moscow, 119571, Russian Federation, e-mail: A_Bessolitsyn@mail.ru

\section{Для цитирования}

Бессолицын А. А. Коммерческое образование в дореволюционной России: перспективы и ограничения / А. А. Бессолицын / / Историко-экономические исследования. 2017. - T. 18, № 3. - C. 423-442. - DOI: 10.17150/23082588.2017.18(3).423-442.

\section{7:4:4}

Bessolitsyn A. A. Commercial Education in Pre-Revolutionary Russia: Perspectives of Development and Limitations. Istoriko-ekonomicheskie issledovaniya $=$ Journal of Economic History $\mathcal{E}$ History of Economics, 2017, vol. 18, no. 3, pp. 423-442. DOI: 10.17150/2308-2588.2017.18(3).423-442. (In Russian). 